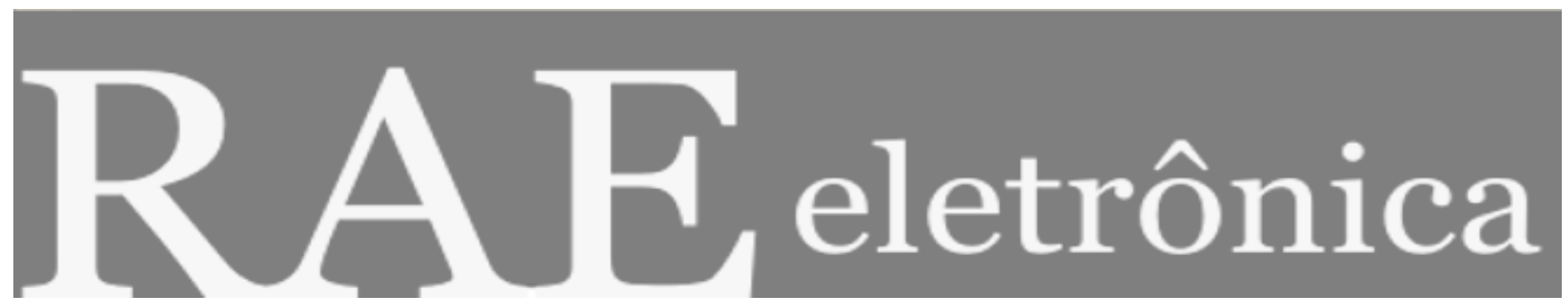

\title{
UMA ANÁLISE CRÍTICA DA DIREÇÃO DA CAUSALIDADE NO BALANCED SCORECARD
}

\author{
Por: \\ Leonardo Fernando Cruz Basso \\ Eduardo Sérgio Ulrich Pace
}

RAE-eletrônica, Volume 2, Número 1, jan-jun/2003.

http://www.rae.com.br/eletronica/index.cfm?FuseAction=Artigo $\& I D=1363 \&$ Secao=CONTRGER $\&$ Volume $=2 \&$ Numer $\mathrm{o}=1$ \&Ano $=2003$

CCopyright, 2002, RAE-eletrônica. Todos os direitos, inclusive de tradução, são reservados. É permitido citar parte de artigos sem autorização prévia desde que seja identificada a fonte. A reprodução total de artigos é proibida. Os artigos só devem ser usados para uso pessoal e não-comercial. Em caso de dúvidas, consulte a redação: redacao@rae.com.br.

A RAE-eletrônica é a revista on-line da FGV-EAESP, totalmente aberta e criada com o objetivo de agilizar a veiculação de trabalhos inéditos. Lançada em janeiro de 2002, com perfil acadêmico, é dedicada a professores, pesquisadores e estudantes. Para mais informações consulte o site www.rae.com.br/eletronica.

RAE-eletrônica

ISSN 1676-5648

(C)2002 Editora: Fundação Getulio Vargas - Escola de Administração de Empresas de São Paulo.

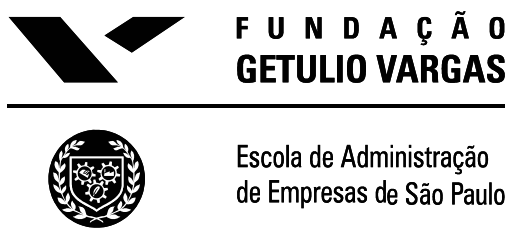




\title{
UMA ANÁLISE CRÍTICA DA DIREÇÃO DA CAUSALIDADE NO BALANCED SCORECARD
}

\section{Leonardo Fernando Cruz Basso}

Ph.D. em Economia pela New School for Social Research - New York

Professor do Programa de Pós-Graduação em Administração de Empresas - PPGAE - da

Universidade Presbiteriana Mackenzie

E-mail:leonardobasso@mackenzie.com.br

Endereço: Rua da Consolação, 896. $7^{\circ}$ andar, sala 73. São Paulo - SP, 01302-907

Interesses de pesquisa: Valoração de Empresas, Competitividade e Macroeconomia

\section{Eduardo Sérgio Ulrich Pace}

Mestre em Administração pela Universidade Presbiteriana Mackenzie

Professor da Faculdade de Ciências Econômicas, Contábeis e Administrativa - FCECA - da

Universidade Presbiteriana Mackenzie

E-mail:pace2@terra.com.br

Endereço: Rua da Consolação, 896, 7 andar - São Paulo - SP, 01302-907

Interesses de pesquisa: Valoração de empresas, Medidas de Desempenho, Organizações do 3 setor.

\section{RESUMO}

Este artigo trata da crescente importância do uso de medidas não financeiras em sistemas de mensuração de desempenho empresarial e avalia as aplicações apresentadas na abordagem contida no balanced scorecard. O alinhamento das medidas numa relação de causa e efeito é apontado como condição essencial para a construção daquele instrumento e para o reconhecimento das medidas não financeiras como direcionadoras de desempenho e de criação de valor. A não verificação daquela relação leva à aceitação de indicadores inadequados e a uma disfunção organizacional. A fundamentação teórica utilizada neste artigo advoga a não existência de uma relação de causa e efeito quando são utilizados critérios científicos para constatar a causalidade. Neste artigo propõe-se, também, que formulações estratégicas e medidas de desempenho sejam consideradas processos paralelos e interativos e, finalmente, são discutidos e apresentados novos critérios para relacioná-las, concluindo-se por uma relação de dupla afetação.

\section{PALAVRAS-CHAVE}

Causalidade no balanced scorecard; direcionadores não financeiros para a criação de valor.

\begin{abstract}
This article refers to the growing importance of the use of non-financial measures in corporate performance measurement systems and evaluates the applications presented in the approach contained in the balanced scorecard. The alignment of measures in a relation of cause and effect is indicated as an essential condition for the construction of that instrument and for the recognition of non-financial measures as performance and value creation drivers. The non-verification of that relation leads to the acceptance of inadequate indicators and to an organizational malfunction. The theoretical grounds employed in this article support the non-existence of a relation of cause and effect when scientific criteria are used to determine causality. This article also proposes that strategic formulations and performance measures be considered parallel and interactive processes. Finally, new criteria are discussed and presented to relate them, concluding on a relation of double affectation.
\end{abstract}


CONTROLE GERENCIAL - UMA ANÁLISE CRÍTICA DA DIREÇÃO DA CAUSALIDADE NO BALANCED SCORECARD

Leonardo Fernando Cruz Basso - Eduardo Sérgio Ulrich Pace

\section{KEY WORDS}

Causality in the balanced scorecard; Non-financial drivers for value creation 


\section{INTRODUÇ̃̃o}

Numa economia de mercado é possível identificar duas formas predominantes de pensamento no campo da administração na busca direcionada para a criação de valor: uma, mais antiga, onde as empresas procuram o máximo lucro para os acionistas e outra que passa a incluir ampla gama de interessados na empresa, os clientes, os próprios acionistas bem como administradores, funcionários, sindicatos, fornecedores, concorrentes e órgãos de representação da sociedade.

No âmbito das empresas, também há a percepção de que um desempenho excepcional estará associado a uma expansão do universo de variáveis com que pretendem aferir seus desempenhos.

Edvinson e Malone (1998:21), constatando o crescimento da importância dos ativos intangíveis, muitas vezes capazes de oferecer uma vantagem competitiva a seus proprietários, apontam para a dificuldade de sua avaliação mais precisa, decorrente da excessiva fundamentação na contabilidade formal.

Muitas empresas, visando competir com sucesso, têm implementado ações de reorganização, aquisição de equipamentos e melhorias de sistemas que são parcialmente retratadas nos seus balanços patrimoniais. Assim, na procura de maior competitividade e de aumento de sua capacidade de gerar lucros elas serão punidas no seu caixa pelos custos de uma visão imediatista, sem que ocorra uma contrapartida do lado dos ativos.

Desta forma, executivos acreditam que o uso exclusivo de apenas uma ou diversas medidas financeiras, distorce a tomada de decisões, propiciando um baixo nível de responsabilização dos administradores.

Medidas financeiras têm sido criticadas por sua natureza histórica capaz de revelar muito sobre as ações passadas, mas pouco ou nada sobre suas capacidades futuras. Paralelamente, houve amplo desenvolvimento dos conceitos de estratégia e da necessidade de aproximá-la das ações, sendo constatado que só as medidas financeiras não atenderiam a essa prioridade, tendo sido buscada uma ligação das medidas não financeiras com a estratégia. .

McNair et al. (1990:30) explicam o sistema de dupla direção da comunicação de objetivos e estratégias, cujas metas financeiras baseiam-se no apoio das atividades diárias não financeiras e financeiras, provenientes dos níveis hierárquicos inferiores. Beischel et al. (1991:26) e Grady (1991:49), também, relacionam medidas financeiras com aquelas não financeiras e introduzem a importância da identificação do conceito de causa e efeito a cada nível da organização, como forma de assegurar a constância de seus objetivos.

Mais recentemente, com o balanced scorecard (BSC) buscou-se integrar as medidas financeiras com as não financeiras, distinguindo-o dos demais instrumentos de medição de desempenho, por conter medidas integradas de ocorrência e direcionadores de tendência, desenhados para capturar a estratégia da organização e ligados por relações de causa e efeito.

Kaplan e Norton (1996:53, 1997:30) identificam quatro passos na implementação do BSC: esclarecendo e traduzindo a visão e a estratégia, - comunicando e estabelecendo vinculações planejando e estabelecendo metas e - aprendizado e feedback estratégico.

O primeiro passo procura desenvolver um entendimento da missão e da estratégia na busca de suas metas. Dado que as afirmações feitas na missão tendem a ser vagas, ela deverá ser traduzida em objetivos específicos e em seguida será desenvolvida uma estratégia que use os pontos fortes da 
organização para alcançar seus objetivos. Neste processo os administradores desenvolverão um conjunto de medidas capazes de capturar a estratégia. Este será o BSC da organização.

Após o desenvolvimento do BSC, como parte do segundo passo, cada unidade estratégica determina suas medidas para o scorecard estabelecendo o processo de comunicação e de ligações, onde os administradores consideram os objetivos estratégicos de suas unidades dentro dos objetivos organizacionais.

Em seguida os administradores definem metas e orçamentos e, no quarto passo, recebem feedback das estratégias das unidades de negócio e da organização ao avaliar seus desempenhos com relação às medidas do scorecard.

Para os autores do BSC ele se constitui num mecanismo para a implementação da estratégia e não para sua formulação, levando-se em conta o conceito de estratégia em Porter (1986:08) definida por um movimento da organização da sua posição atual para uma desejável, mas incerta posição futura, onde "há uma escolha dos segmentos de mercado e clientes que as unidades de negócio pretendem servir, identificando processos internos críticos e nos quais ela deve atingir a excelência para concretizar a entrega de valor aos seus clientes alvo" e onde, a estratégia competitiva seria dirigida pelo meio (Kaplan e Norton, 1997:38).

“A formulação de grandes estratégias é uma arte..., mas sua descrição não o é. A estratégia descrita numa forma mais disciplinada pode aumentar a probabilidade de sucesso na sua implementação", (Kaplan e Norton, 2000:176). Para tanto, o caminho será de hipóteses interligadas, descritas no mapa da estratégia, especificando as relações de causa e efeito, tornando-as explícitas e passíveis de verificação através de medidas corporativas.

Epstein e Birchard (2000:154), entre os elementos relacionados para uma seleção de medidas, apontam para a necessidade de se ligar as medidas da administração central a toda a organização, incentivando as chefias de unidades a criarem sua família de medidas alinhadas entre aquelas e as de seus funcionários e equipes e, nesse mesmo sentido, em cascata por toda a organização. O que se deve buscar são medidas que criem valor através das inter-relações entre os stakeholders.

Como é sabido, medidas perdem seu significado com o tempo, porque o desempenho das pessoas melhora, deixando de servir como objetivos ou metas mais exigentes. Assim, medidas, também precisam variar. Aquelas não financeiras poderão superar essa limitação se forem capazes de se dirigirem e dirigirem as medidas financeiras.

Epstein aponta a necessidade da empresa conciliar a procura de consistência pelas pessoas com relação às mudanças contínuas da empresa. Existirão muitos e variados indicadores internos de desempenho (dias decorridos) com externos (satisfação de clientes), medidas de input (R\&D) com medidas de processos e de output (produtividade), que deverão ser reduzidos a poucos e vitais, de modo a indicar se a estratégia está sendo alcançada. Dado que as medidas trabalham juntas para criar valor, a tarefa dos administradores será de zelar para que seus gerentes operacionais compreendam as ligações entre elas, do contrário não terão seu apoio.

Para Norreklit (2000:68), a hipótese da existência de uma relação de causa e efeito é essencial, pois possibilita que medidas não financeiras sejam utilizadas para prever o futuro desempenho financeiro.

A validação do modelo do BSC dependerá da hipótese de existência de uma relação de causa e efeito entre as medidas, como já citado. O objetivo deste trabalho é mostrar, à luz dos critérios estabelecidos para se determinar causalidade, que não existe uma relação causal entre áreas de 
medição sugeridas por Kaplan e Norton (2000:65). Entretanto, a aplicação de modelos de caminho causal pode produzir direcionadores de desempenho não financeiros capazes de criar valor.

A avaliação da direção de causalidade é de extrema relevância para os que se preocupam com gestão empresarial, pois caso ocorram da forma preconizada por Kaplan e Norton, medidas não financeiras podem ser utilizadas como direcionadoras dos desempenhos financeiros e assim sendo como direcionadoras da criação de valor para o acionista, uma das preocupações de qualquer gestor empresarial.

Ocorre que a noção de causalidade seqüencial e linear é meramente assumida pelos participantes do diálogo estratégico e consistente (consistente, pois os participantes fazem uso de sua "linguagem"), dado que sua validade só é demonstrável ex post, quando já é conhecido o (in)sucesso dos resultados. Logo, direcionadores do desempenho futuro, influenciados por hipóteses incorretas poderão distorcer os indicadores de desempenho a serem adotados com conseqüências no nível dos resultados, conforme de Haas et al. (1999:243).

Este artigo dedicou uma seção à análise dos critérios para se estabelecer causalidade, aplicando-os ao trabalho de Kaplan \& Norton. Concluiu-se pela existência de uma relação de dupla afetação quando analisada a relação existente entre o cliente e o desempenho financeiro da empresa. A satisfação do consumidor afeta o desempenho financeiro e o desempenho financeiro, ainda que não diretamente, impacta na satisfação do consumidor.

Poderão existir, contudo, medidas de avaliação da satisfação do consumidor capazes de direcionar num único sentido a criação de valor, podendo ser medidas financeiramente. Isto demonstra a dificuldade de se estabelecer causação no universo das pesquisas empresariais.

Metodologias similares ao BSC, buscando não descartá-lo, mas aprimorá-lo, foram desenvolvidas para assegurar a conexão eficiente entre os objetivos maiores de longo prazo com os projetos e planos de ação operacionais, o que será alcançado com as melhorias essenciais dos processos e das competências ao se internar ativos intangíveis.

Como alternativa às metodologias que enfatizam a causalidade surge a metodologia OVAR (Objetivos, Variáveis para a ação e Responsabilidades) desenvolvida por Michel (1998) que responde a três tipos de necessidades:

- "Gerir o desempenho": ao permear as questões estratégicas e os objetivos pelos centros de responsabilidade da organização; trata-se de um processo que busca ligar a estratégia com os planos operacionais e projetos desenvolvidos pelos gestores;

- "Implementar uma estrutura formal de diálogo entre os gestores", sejam eles de negócios ou funcionais: trata'se de uma ferramenta que induz à discussão para a obtenção de um consenso sobre metas de responsabilidade comum e de como alcançá-las;

- "Desenvolver uma rotina de relatórios operacionais" (vide o Tableaux de Bord) selecionando indicadores financeiros e não financeiros para apresentar interna e externamente, acompanhando planos de ação vinculados a cada objetivo (de curto e longo prazo), QUADRO 1.

Ela consiste em antecipar resultados dos planos operacionais, propondo uma compreensão mais clara das possíveis relações de causa e efeito. Os objetivos constituem-se em áreas de resultado da organização, as variáveis para a ação compõe os elementos operacionais-chave, subordinadas à responsabilidade dos gestores, devendo ser controladas, pois constituem as causas reais da consecução dos objetivos, conforme é sugerido no GRÁFICO 1. Controladas pelos gestores 
( haverá um número limitado de variáveis para ação ) elas representam um número restrito de "causas" que constituem a raiz do desempenho (crescimento com valor).

Estas variáveis constituem a plataforma para os principais planos de ação ou projetos a serem geridos ao longo da hierarquia: a metodologia OVAR enfatiza o desempenho transversal e rompe com os espaços vazios de comunicação entre os centros de responsabilidade, conforme pode ser visto no GRÁFICO 2. Objetivamente, cada gestor constrói sua grade OVAR, inclusive nos níveis superiores da hierarquia, questionando-se: como se posicionam face ao proposto, como compreendem e interpretam a congruência dos objetivos. Diferenças de percepção deverão surgir ao se realizar uma comparação compartilhada das grades, produzindo soluções para conflitos entre os gestores, procurando superar os aspectos do jogo político sempre presente nas empresas (o que eu ganho, o que eu perco se...).

O produto final deste processo será um conjunto de informações proveniente dos indicadores não financeiros essenciais à gestão interna e que, com uma seleção correta, comporão a base para a divulgação externa aos acionistas e analistas financeiros. Trata-se de instrumento relevante da governança corporativa, componente dos objetivos estratégicos de responsabilidade dos gestores, que permitirá identificar fontes efetivas de criação de valor para os stakeholders.

Exemplificando, conforme o GRÁFICO 2, da empresa Fusiman (FR), foram definidas as variáveis para a ação, face aos objetivos de maior participação de mercado, ROCE e geração de valor.

Para ampliação da participação de mercado foram identificadas as variáveis:

- preços: diferenciação de preços, margem de lucro total, por U.N., por área, proteção de margem/ de mercado;

- propaganda: segmentação do público-alvo, tempo, retorno esperado;

- promoção: descontos, ações no ponto de venda, tempo, amplitude;

- novos produtos: público-alvo, estrutura de pós-venda, níveis de qualidade, \% das vendas, $\%$ de mercado;

- força de vendas: número de pessoas, distribuição física, recrutamento / treinamento;

Para a alcançar um determinado ROCE:

- custos: de produção, de qualidade, de serviços, diretos/indiretos;

- investimentos: volume de capital de terceiros e de capital próprio;

- estoques: de matérias-primas, de produtos acabados, tempos, rotação, condicionantes físicas;

- recebíveis: qualidade dos recebimentos; liquidez, velocidade;

- fornecedores: poder de barganha, qualidade, imagem, segurança;

Para alcançar uma determinada geração de valor:

- custos: gestão do contas a pagar e a receber, economias de escala, análise da cadeia de valor, distribuição, condições de serviços e de garantias;

- investimentos: outsourcing, ganhos de produtividade, licenciamento, franquias, inovação tecnológica;

- estoques: apropriação dos custos diretos e indiretos de carregamento dos diferentes estoques

- recebíveis: redução do contas a receber, gestão do caixa; 
- fornecedores: rearranjo das ligações na cadeia de valor, pontos de contato com a cadeia de valor dos fornecedores;

- custo de capital: custos das fontes, disponibilidade, diversificação, margem x custos de capital;

As responsabilidades pelos projetos ou planos de ação estão definidas na seqüência do GRAFICO 2.

\section{Gráfico 1 : A Metodologia OVAR}

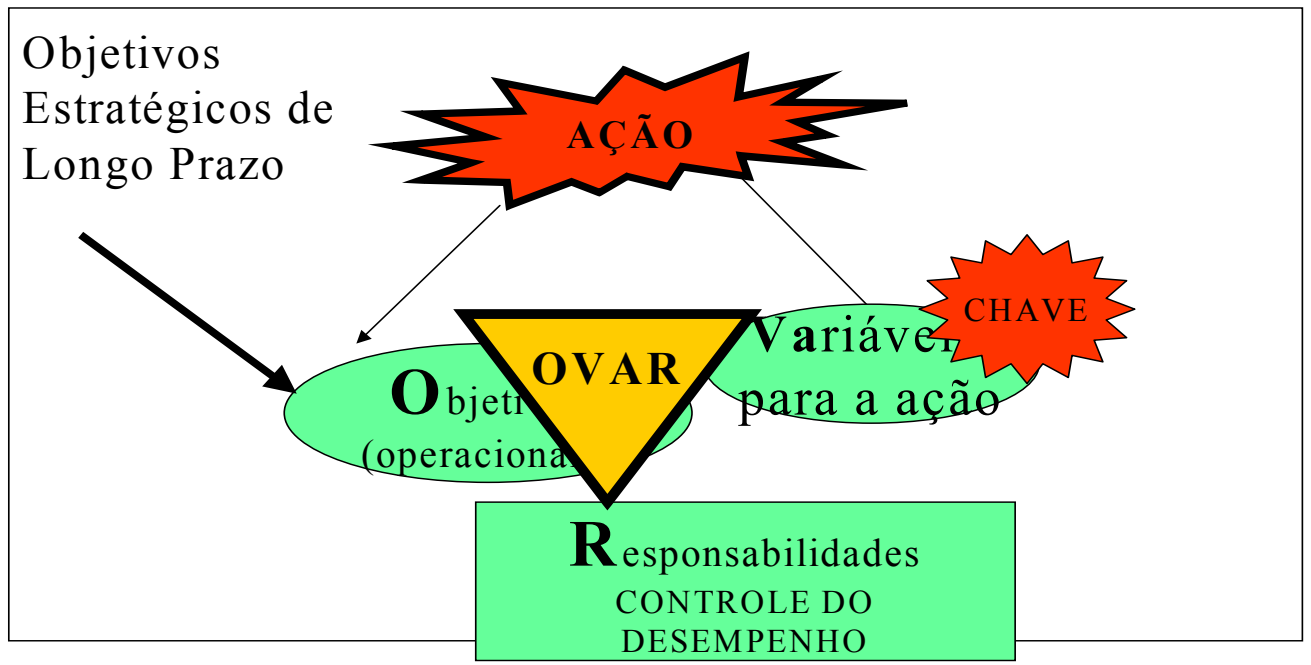

Fonte: Adaptado de MICHEL, D. Le Contrôle de Gestion, HEC, Dunod, 1998

\section{Quadro 1 - Objetivos na Ótica da Metodologia OVAR}

OBJETIVOS DO OVAR

- gerir o desempenho, as questões estratégicas e os objetivos pelos centros de responsabilidade da organização (de lucro ou não) ====> IMPLICAÇÕES PARA A ÁREA DE RECURSOS HUMANOS

\footnotetext{
- Implementar uma estrutura formal de diálogo entre TODOS os gestores, (unidades de negócios ou funcionais): ====> TRATA-SE DE PROCESSO DE CONGRUÊNCIA DAS METAS SUSTENTÁVEIS

-desenvolver uma rotina de relatórios operacionais ====>USO DE INDICADORES NÃO FINANCEIROS COM PLANOS DE AÇÃO (de curto e de longo prazo)
}

Fonte: Adaptado de MICHEL, D. Le Contrôle de Gestion, HEC, Dunod, 1998 
Gráfico 2 - Da Estratégia para a Ação

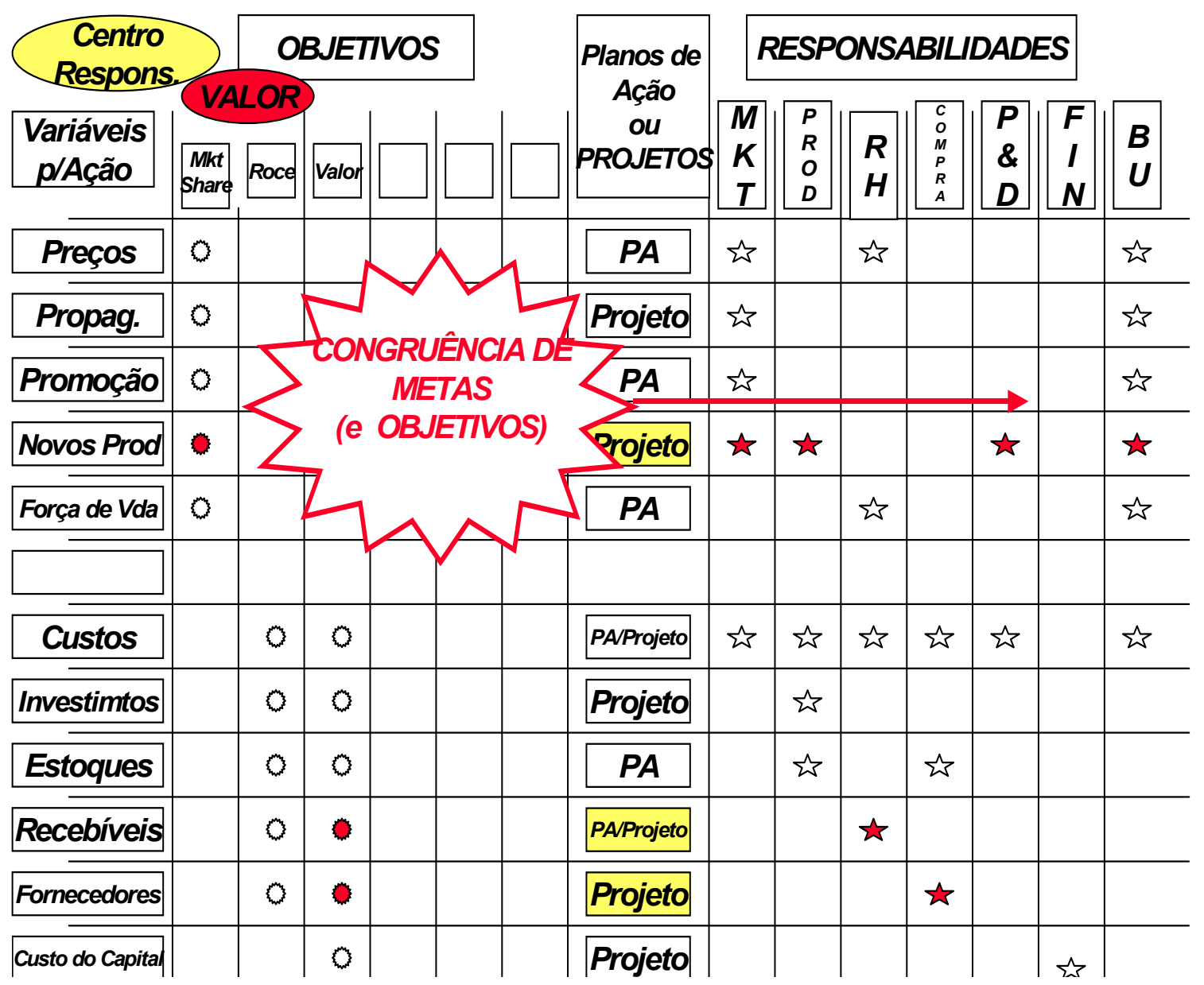

Fonte: Adaptado de MICHEL,D. Le Contrôle de Gestion, HEC, Dunod, 1998

\section{Referencial Teórico - ANÁlise da RelaÇão de CAUSA E EFEITo no BaLANCED SCORECARD}

Em economia, administração e ciências correlatas existem basicamente dois tipos de situações para testes de causalidade (Granger, 1998).

No primeiro, uma população de agentes econômicos é submetida à observação e algumas variáveis consideradas relevantes são mensuradas. Granger, in Palgrave (1998:380-382), utiliza como exemplo o montante de eletricidade utilizado por uma família (household). A totalidade das medidas fornece uma distribuição. Uma questão pode ser colocada: porque uma família utiliza mais eletricidade que outra?

Está é uma questão de causalidade de dados de corte (cross-sectional causality question). Ocorre em um ponto específico do tempo, daí a palavra corte.

Poder-se-ia perguntar, também, porque o consumo de uma família (ou distribuição de famílias) muda com o tempo.

Este tipo de questionamento se insere no que se denomina questões de causalidade temporal. Grande parte dos estudos em administração lidam com causalidade temporal, levando a priorizar este tipo de causalidade. Há uma diferença entre mera associação e uma relação causal. 
Uma correlação é uma mera associação entre um par de variáveis, mas uma correlação não basta para determinar uma causação porque é uma relação simétrica. Isto quer dizer que a extensão pela qual $\mathrm{X}$ é correlacionado a $\mathrm{Y}$ é exatamente a mesma pela qual $\mathrm{Y}$ é correlacionado ou explicado por Y, ou seja é uma relação simétrica. Para quebrar a relação simétrica, é necessário construir uma relação não simétrica.

As respostas dos que se debruçaram sobre o problema não é unânime, mas existem algumas exigências (critérios) (Granger, 1998):

a) antecedência no tempo da variável que é considerada causa;

b) eventos logicamente independentes;

c) controlabilidade;

d) uma teoria relevante;

e) previsibilidade;

f) conhecimento exterior (outside knowledge) ou exogeneibilidade da variável que é considerada causa;

Abaixo cada critério será examinado detalhadamente.

\section{a) Antecedência no tempo da variável que é considerada causa}

Norreklit (2000) utiliza os critérios de David Hume para estabelecer uma relação de causa e efeito. Os critérios são:

1. X precede $\mathrm{Y}$, cronologicamente falando;

2. a observação do evento $X$ necessariamente ou com grande probabilidade implica em outra observação do evento $\mathrm{Y}$ e os dois eventos podem ser observados em um período de tempo pequeno. Seria válido no que concerne ao espaço da observação dos eventos, o que será ignorado aqui pela dubiedade da afirmação, dado que a velocidade da informação e de transporte, por exemplo, tornam o consumidor brasileiro próximo do mercado americano para fins de pesquisas administrativas.

Prioridade temporal para Granger (1998) significa a observância de duas afirmações:

3. A causa não pode ocorrer depois do efeito

4. A causa ocorre antes do efeito

Estas duas afirmações casam perfeitamente bem com o propósito dos testes estatísticos, que devem ser realizados utilizando-se dados já observados de variáveis. Entretanto Hicks (1919) não concorda com a assertiva 4) argumentando que os modelos de equilíbrio utilizados em economia são estático-comparativos, onde causa e efeito ocorrem simultaneamente pois não utilizam a variável tempo. Para nossos propósitos aqui, é suficiente saber que os modelos lógicos podem ser transformados em modelos dinâmicos (onde a variável tempo é introduzida explicitamente) e que isto reforça nossa crença de que o conceito de prioridade temporal deve englobar as assertivas 1 (que é o mesmo que as assertivas 3 e 4 ) e 2.

Simon (1970) vai mais além argumentando contra o critério de antecedência temporal como um critério relevante para categorizar causação.

$\mathrm{O}$ argumento pode ser entendido com a ajuda de um exemplo: deseja-se explicar o aumento da demanda por brinquedos em novembro em relação a outubro; uma constatação que se observa acontecer ano após ano. 
Esta relação pode ser explicada pela maior proximidade de novembro em relação ao Natal, pois as pessoas antecipam suas compras. Sendo isto verdade, são as festividades natalinas, um evento que ainda não ocorreu, que explicam um evento que pode estar ocorrendo agora. Neste caso a causa sucede o evento, temporalmente falando.

Isto ocorre sempre que expectativas acerca do futuro não apresentam relações com fatos passados (como por exemplo, previsões acerca do comportamento da taxa de câmbio, querem sejam suportadas por teorias expectacionais, ou seja, baseadas em expectativas, ou meras apostas) ou expectativas acerca do futuro suportadas por eventos passados, como é o caso do crescimento da demanda que ocorre nos meses que precedem o Natal, apresentando um volume maior de vendas quanto mais próximo do mesmo.

Esta argumentação deixa em posição desconfortável o critério de antecedência temporal para verificar se uma variável é causa de outra.

Simon (1970) não acredita que as exceções sejam poucas e abandona o critério de antecedência no tempo.

Adotando-se aqui uma posição mais pragmática, será buscado suporte em uma teoria com boa fundamentação para estabelecer a causação, abandonando-se o critério de antecedência temporal, sempre que a teoria assim o exigir. Entretanto, para todos os casos em que a antecedência temporal for justificada por uma teoria fortemente estruturada, ela será considerada como critério relevante.

\section{b) Eventos logicamente independentes}

Em uma relação de causa e efeito os eventos X e Y devem ser logicamente independentes. O significado de lógica aqui é que não se pode, racionalmente, ou seja, a partir de uma construção lógica, inferir $\mathrm{Y}$ a partir de $\mathrm{X}$.

Um exemplo pode ser retirado da teoria do consumidor e que questiona a relação de casualidade proposta por Kaplan e Norton.

A teoria do excedente do consumidor procura responder à questão do montante pelo qual uma alteração de preço melhora a posição de um consumidor. O excedente do consumidor, Rosen (1995) pode ser visualizado e compreendido com a ajuda do Gráfico 3.

Supondo-se que o preço de uma maçã é $\mathrm{P}_{0}$ e que decresça para $\mathrm{P}_{1}$. Os consumidores estão mais satisfeitos, sendo possível estipular um montante em reais para a melhora. A curva $D_{a}$ representa a curva de demanda por maçãs.

Assumindo-se que os consumidores estejam em um mundo com capacidade produtiva disponível para atender a um aumento de demanda, ou seja, a oferta não é um problema, e é representada pela curva de oferta elástica $S_{a}$.

Considerando-se estas suposições, quando o preço é $\mathrm{P}_{0}$ a quantidade demandada é $\mathrm{a}_{0}$. Imaginando-se um aumento da capacidade de produzir maçãs, representando uma queda no preço da maçã $\left(\mathrm{P}_{1}\right)$, sendo que a produção aumenta para $\mathrm{a}_{1}$.

Pergunta-se quanto os consumidores estariam dispostos a pagar pelo privilégio de consumir $\mathrm{a}_{1}$ maçãs a um preço $\mathrm{P}_{1}$ em vez de $\mathrm{a}_{0}$ a um preço $\mathrm{P}_{0}$. Para fornecer uma resposta satisfatória deve-se enfatizar que a curva de demanda mostra o montante máximo que os indivíduos estariam dispostos a pagar pelas maçãs que consomem. 
Tomando-se arbitrariamente uma quantidade de maçãs $a_{2}$, o máximo que os consumidores estão dispostos a pagar é representado pela distância $\mathrm{m}_{\mathrm{n}}$. No preço $\mathrm{P}_{0}$ os consumidores pagam efetivamente $m_{c}$, obtendo um excedente de satisfação de $n_{c}$.

O montante pelo qual o valor que os consumidores estão dispostos a pagar excede o montante que realmente pagam, é conceituado como excedente do consumidor.

A soma dos excedentes para todas as quantidades resulta no excedente do consumidor total. Quando o preço é $\mathrm{P}_{0}$ ele é representado pela área $\mathrm{P}_{\text {oed }}$. Quando o preço é $\mathrm{P}_{1}$ ele é representado pela área $\mathrm{P}_{1 \mathrm{eg}}$.

A diferença entre as áreas mede, em termos monetários, o quanto o consumidor está melhor quando cai o preço.

Conclui-se, conforme aponta Norreklitk (2000: 74), que quando compra alguma coisa, o consumidor aufere um excedente e já está satisfeito.

A única forma de escapar desta relação lógica é associar satisfação com outro significado que não seja o oriundo da teoria econômica do consumidor, incorporando aspectos psicológicos que abranjam não só o produto como o atendimento e o meio ambiente em que está estabelecido o negócio.

\section{Gráfico 3 - Mensuração do Excedente do Consumidor}

Preço das maçãs

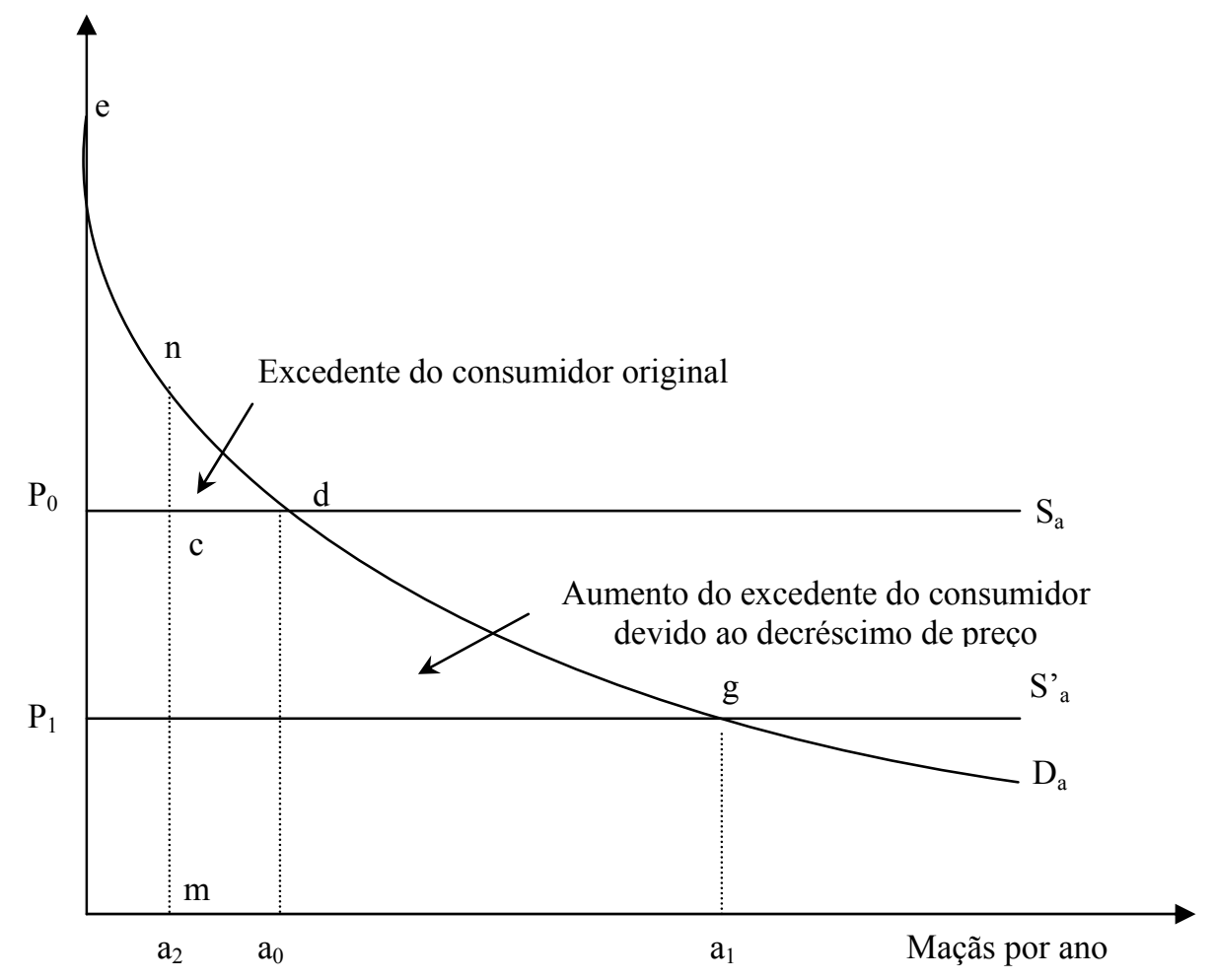

Fonte: Rosen, Haryey S.; Public Finance, Irwin, 1995, pág. 57.

\section{c) Controlabilidade}


No que concerne ao conceito de controlabilidade para definir uma relação causal considera-se que:

$\mathrm{X}$ é a causa de $\mathrm{Y}$, se, por hipótese é ou seria possível, ao se controlar $\mathrm{X}$, indiretamente controlar $\mathrm{Y}$, ao menos estocasticamente, mas não é, ou não seria possível, ao se controlar $\mathrm{Y}$, indiretamente controlar $\mathrm{X}$.

A controlabilidade é por alguns cientistas considerada mais forte que uma relação causal. A razão é que podem ocorrer situações em que na tentativa de controlar uma variável considerada causa pode-se destruir a relação causal.

\section{d) Uma teoria relevante}

No que concerne a uma teoria bem fundamentada, não pode haver discordância. Sem uma teoria bem fundamentada, recairíamos no mundo das hipóteses empíricas, Köcke (1997), que não é aceitável para aqueles que crêem no método científico, Kerlinger (1980). Isto se torna ainda mais relevante face ao fato de que antecedência temporal nem sempre é relevante para se estabelecer causação, necessitando-se de uma teoria bem fundamentada para se justificar a antecedência temporal.

\section{e) Previsibilidade}

Granger (1998) cita o trabalho de Arnold Zellner, que se sustenta no trabalho do filósofo H. Feigl, que argumenta que o conceito de causalidade é definido em termos de previsibilidade sujeita a uma lei. Acredita-se que a incorporação da previsibilidade aproxima este grau de crença à visão dos monetaristas que afirmam que o grau de importância de uma teoria é mensurado pelo seu poder de previsão, Friedman (1953). Teorias que são falseadas constantemente devido ao fraco poder de previsão não deveriam ser enquadradas no rol das teorias bem fundamentadas.

\section{f) Conhecimento Externo (Variáveis Exógenas)}

Outra variável utilizada para categorizar causalidade é o conhecimento externo (outside knowledge). Dentro do conhecimento externo estão englobadas as variáveis geradas fora do sistema para o qual procura-se descobrir as variáveis que são causas para outras variáveis.

A informação externa é utilizada para quebrar a simetria de associação, estabelecendo desta forma uma relação causal. Estas variáveis são denominadas de variáveis exógenas e serão aqui exploradas porque questionam a causalidade proposta por Kaplan e Norton.

Para uma variável ser considerada exógena ela não pode ser afetada pela variável para a qual se supõe ser uma causa, Simon (1998). Assim acredita-se que o montante de chuva determina o tamanho da colheita, não sendo possível assumir que o montante de chuva seja afetado pela extensão da área cultivada, pois caso isto ocorra estará sendo quebrada a assimetria pré-suposta na causalidade.

No modelo de Kaplan \& Norton (1997:31) a relação causal é: medidas de aprendizado e crescimento; $\Rightarrow$ medidas de processos internos; $\Rightarrow$ medidas da perspectiva dos clientes; $\Rightarrow$ medidas financeiras, onde a seta indica a direção da causalidade.

Kaplan e Norton (1996: 5; 157) não são muito claros neste ponto, pois sugerem que o resultado financeiro afeta o primeiro elo da cadeia de causação, o que por afetações subseqüentes implica em que o resultado financeiro afeta o consumidor. 
Desta forma as relações entre as perspectivas seriam de interdependência onde, por exemplo, o desenvolvimento dos processos internos dependeria dos resultados financeiros (para investir em pesquisa e desenvolvimento, necessita-se de bons resultados financeiros), mas pesquisa e desenvolvimento são necessários para produzir bons resultados. Existe um raciocínio circular e uma relação de interdependência, (Norreklit, 2000:75)

Contudo, essas relações podem ser visualizadas como dispostas na Figura 1.

\section{Figura 1 - Representação de Causalidade no Balanced Scorecard}

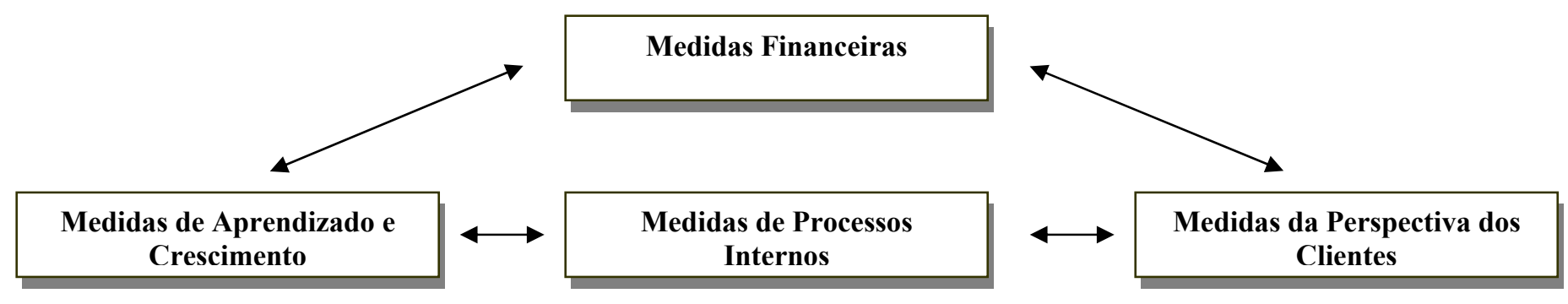

Fonte: Kaplan, Robert, Norton, D., 1997, Estratégia em Ação: Balanced Scorecard, Campus, pg 31

Nesta figura, apresentada pelos autores, acredita-se identificar uma relação de finalidade e não de causalidade, que seria a forma Kaplan e Norton de conceber a relação de causa e efeito. A finalidade, que é mais ambígua e complexa, ocorre quando as ações humanas, seus desejos e sua visão estão inter-relacionados, ou seja, quando uma pessoa acredita que uma ação é o meio para atingir um fim; o fim e aquela crença provocam a ação (Follesdal, 1997) apud Norreklit (2000:76).

Neste caso diferentes meios podem ser utilizados na busca de um fim, não existindo apenas uma lei, como na causalidade, a partir da qual deriva-se que ações levarão a um bom resultado financeiro.

Adicionalmente, ao se aceitar os fundamentos da teoria da utilidade para determinar a satisfação do consumidor, a relação entre satisfação do consumidor e resultado financeiro é lógica e não causal Norreklit (2000:73). Em outras palavras pode ser inferida por meio de um raciocínio lógico, não necessitando de comprovação empírica. Mas mesmo assim os testes empíricos são essenciais para quantificar a relação.

Por exemplo, ao se afirmar que o consumo dos indivíduos é função da renda auferida pelos mesmos, não se pode dizer em quanto um aumento da renda afeta o aumento do consumo, a não ser que se faça uso de procedimentos econométricos ou de análise de dados multivariados.

Um destes métodos é denominado de modelo de caminho causal (causal pathway modeling) e foi aplicado com sucesso na Sears, Roebuck and Company, Rucci et al. (1998).

Esta metodologia distingue-se de uma simples análise de correlação porque procura estabelecer causação entre as variáveis. Utilizando-se de análise de agrupamentos (cluster analysis) e análise de fatores (factor analysis) ela procura estabelecer conexões fortes e fracas entre as variáveis. Utiliza-se a palavra conexão para evitar o uso da palavra causação, pois os critérios para se estabelecer causação são mais fracos que os preconizados pela ciência. 
No caso da Sears verificou-se empiricamente que, um aumento de cinco unidades na atitude dos empregados, produzia 1,3 unidades de aumento na impressão dos consumidores o que por sua vez produzia $0,5 \%$ de aumento no crescimento das receitas. Neste caso, foi usada a palavra impressão propositalmente para evitar a palavra satisfação que, como mostrado, apresenta uma relação lógica, portanto não causal, com o resultado financeiro. Este resultado foi estabelecido com bastante acurácia, a ponto da Sears utilizar com sucesso indicadores de desempenho não financeiros como direcionadores da criação de valor.

O modelo de caminho causal se insere no grupo dos modelos de equações estruturais. No Structural Equation Modelling causação é definida em termos de:

a) grau de associação (correlação) satisfatório entre as variáveis;

b) uma variável ocorre antes da outra (precedência no tempo);

c) não existem outras causas razoáveis que expliquem o resultado.

É necessário estar cientes, entretanto, que nestes modelos a causação é especificada a priori, podendo ser alterada, dependendo dos coeficientes de correlação obtidos, o que não se insere no conceito de causação preconizado pelos cientistas.

Entretanto, dado um conjunto de duas variáveis ( $\mathrm{X}$ e $\mathrm{Y}$ ) que se afetem reciprocamente com defasagens, é possível tentar-se determinar se $\mathrm{Y}$ causa $\mathrm{X}$, se $\mathrm{X}$ causa $\mathrm{Y}$ ou se ocorre uma realimentação entre estas duas variáveis. Por esta descrição pode-se observar que o conceito de causação aqui é distinto do estabelecido pelos critérios para se estabelecer causação (antecedência temporal, independência lógica, teoria relevante, variáveis exógenas, controlabilidade e previsibilidade) porque se partiu do pressuposto que as variáveis se afetam reciprocamente.

O teste de casualidade de Granger, Gujarati (2000) envolve a estimação de duas regressões:

$$
\begin{array}{ll}
Y_{t}=\alpha \cdot X_{t-1}+\beta . Y_{t-1}+\mu \cdot 1 t & \text { [Equação 1] } \\
X_{t}=\lambda \cdot X_{t-1}+\delta . Y_{t-1}+\mu_{.2 t} & \text { [Equação 2] }
\end{array}
$$

onde $\mu_{2 \mathrm{t}} \mathrm{e} \mu_{1 \mathrm{t}}$ não são correlacionados.

A Equação 1 acima postula que o $\mathrm{Y}$ atual se relaciona com os valores passados do $\mathrm{Y}$ e também de X. A Equação 2 postula um comportamento similar para X. Notar que essas regressões podem ser dispostas em formas de crescimento, distintos em quatro casos:

1. Causalidade unidirecional de $\mathrm{X}$ para $\mathrm{Y}$ é indicada se os coeficientes estimados sobre o $\mathrm{X}$ defasado na Equação 1 forem estatisticamente diferentes de zero como um grupo (isto é, $\Sigma \alpha_{i} \neq 0$ ) e o conjuntos dos coeficientes estimados sobre o $\mathrm{Y}$ defasado na Equação 2 não forem estatisticamente diferentes de zero (isto é, $\Sigma \delta_{i}=0$ ).

2. Inversamente, causalidade unidirecional de $Y$ para $X$ existe se o conjunto de coeficientes defasados de $\mathrm{X}$ na Equação 1 não for estatisticamente diferente de zero (isto é, $\Sigma \alpha_{i}=0$ ) e o conjunto dos coeficientes defasados de Y na Equação 2 for estatisticamente diferente de zero (isto é, $\left.\Sigma \delta_{\mathrm{i}} \neq 0\right)$.

3. Realimentação, ou casualidade bilateral, é sugerida quando os conjuntos de coeficientes de $\mathrm{X}$ e Y são estatística e significativamente diferentes de zero em ambas as regressões.

4. Por fim, independência é sugerida quando os conjuntos de coeficientes de $\mathrm{X}$ e $\mathrm{Y}$ não são estatisticamente significativos em ambas as regressões. 
Mais genericamente, como se assume que o futuro não pode prever o passado, se a variável $\mathrm{X}$ causa (no sentido de Granger) a variável Y, então mudanças em X devem preceder mudanças em Y. Portanto, em uma regressão de Y sobre outras variáveis (incluindo seus próprios valores passados), se forem incluídos os valores passados ou defasados de $\mathrm{X}$ e isso melhorar significativamente a previsão de $Y$, pode-se, então, dizer que X causa (no sentido de Granger) Y. Uma definição similar se aplica se Y causa (no sentido de Granger) X. Testes de casualidade como estes são de extrema importância quando se procura verificar empiricamente o que é causa de que. Entretanto, como já foi alertado, o fato das variáveis poderem se afetar reciprocamente não está no espírito do conceito científico de causa. Estes testes seriam de extrema utilidade para a sugestão do critério que se deseja incorporar como um dos essenciais para estabelecer causalidade, ou seja, a afetação direta, o que será examinado na conclusão.

\section{CONCLUSÕES}

O objetivo deste artigo foi o de examinar a argumentação de Kaplan e Norton de que existe uma relação de causalidade no BSC. ordem:

O modelo de Kaplan e Norton (1997:31) as relações causais podem ser expressas na seguinte

- medidas de aprendizado e crescimento são causadoras de medidas de processos internos, que por sua vez produzem medidas da perspectiva dos clientes, que por sua vez dão origem aos resultados financeiros (ou medidas financeiras).

Estes elos de causalidade se sustentam tomando-se como base os critérios para se estabelecer uma relação de causalidade?

Examine-se cada um dos critérios pela ordem de apresentação no texto.

O primeiro é relativo à antecedência temporal. A variável que é considerada causa deve anteceder, temporalmente falando a variável que é considerada conseqüência.

A própria argumentação de Kaplan e Norton pode ser utilizada para questionarmos a antecedência temporal, pois os próprios autores sugerem que o resultado financeiro afeta o primeiro elo da cadeia de causação, o que por afetações subseqüentes implica que o resultado financeiro afeta o consumidor.

A favor de Kaplan e Norton poder-se-ia utilizar a argumentação de Simon, descartando a antecedência temporal como um critério relevante, mas isto seria de pouca utilidade, porque se não antecede, sucede, e no caso em questão ocorre a manifestação de ambos fenômenos, pois tanto a satisfação do consumidor afeta o desempenho financeiro como o desempenho financeiro afeta o consumidor.

No que concerne à necessidade dos eventos serem logicamente independentes, a argumentação de Norreklit é devastadora contra a argumentação de Kaplan e Norton: considerandose o referencial microeconômico, quando um consumidor compra esta realizando um excedente e, portanto, esta satisfeito.

Quanto à controlabilidade, este é um critério que necessita de experimentos práticos,ou seja , necessita de manipulação dos dados. Este critério joga a favor de Kaplan e Norton, pois a implantação do modelo de causação na Sears (Rucci et al., 1998) demonstra que é possível quantificar em quanto uma alteração na impressão do consumidor altera os resultados financeiros (alteração medida quantitativamente). 
O critério de teoria relevante, no que concerne especificamente à causalidade não é obedecido por Kaplan e Norton, pois os autores não examinam de maneira consistente os critérios da necessidade dos eventos serem logicamente independentes, não apresentando uma discussão sobre previsibilidade.

Para exaurir o exame dos critérios, o ultimo, que trata da unidirecionalidade da relação de causa e efeito é o mais devastador contra as pretensões da argumentação; para que uma variável seja causa de outra, ela não pode ser afetada pela variável para a qual se supõe ser a causa. Se as variáveis se afetam mutuamente, estará senda quebrada a assimetria pressuposta na causalidade.

Uma solução para o dilema é adotar a causalidade no sentido de Granger, mas conforme enfatizado no texto, o fato de duas variáveis se afetarem conjuntamente nada tem a ver com o conceito aceito cientificamente para se determinar causalidade.

Fazendo um resumo do exposto, pode-se afirmar que a argumentação proposta apresenta de forma inquestionável a inexistência de causalidade no modelo proposto. Assim sendo, caberia indagar quais são as alternativas.

Uma primeira opção seria abandonar um critério relevante para conceituar causalidade, ou seja, as variáveis não podem se afetar mutuamente. Nesse sentido pode-se trabalhar com a causalidade de Granger, onde as variáveis podem ser afetadas mutuamente, mas de onde pode-se extrair resultados interessantes, como por exemplo, a magnitude pela qual uma a alteração em uma variável altera outra variável, como por exemplo no modelo da Sears.

Uma segunda alternativa, com Norreklit (2000: 83), reside em estabelecer uma coerência entre as medidas ao invés de ver essas relações como causais.

A coerência busca saber se há complementação ou ajuste entre os fatores relevantes. Por exemplo, uma ação será coerente se as ações e os meios usados são apropriados para o fim pretendido. Portanto, é condição obrigatória para se alcançar determinado resultado, o acesso aos fatores que permitam realizar aquele resultado.

Dois são os níveis apontados por Norreklit para uma aplicação do conceito de coerência: 1- o nível da formulação estratégica contendo os aspectos relativos à coerência entre as áreas; 2- o nível das atividades onde procura analisar a extensão da coerência entre recursos e desempenho. Portanto, a formulação estratégica e o sistema de controle de desempenho devem ser vistos como processos paralelos e iterativos, onde a coerência seria um atributo de um sistema de medidas de desempenho que provoca resultados no grupo que as utiliza e contribui para o desempenho de outros grupos interdependentes e desse modo para o desempenho global da instituição.

Nessa mesma linha, Norreklit afirma que ao invés de buscar ver causalidade entre as medidas não financeiras, seria útil o estabelecimento de coerência entre as medidas, pois ela foca quanto os fenômenos relevantes coincidem ou quanto eles se complementam. Assim, uma ação será coerente se as ações e os meios usados são adequados com relação aos fins desejados. Portanto, uma condição para alcançar um fim será ter acesso aos fatores capazes de concretizá-lo.

No caso de administradores ou funcionários, a condicionante será ter acesso aos métodos que lhes permita controlar os fatores e, assim obter os fins desejados. A falta de coerência produz condições insuficientes par alcançar o fim desejado. Portanto, o bom conhecimento dos meios e dos fins condicionam a capacidade de julgar se há coerência e prever resultados. 
Não concordando que a causação possa ser inferida na maneira que foi proposta por Kaplan e Norton, Norreklit propõe o critério da coerência entre as medidas de desempenho, recursos e estratégias, mas não estabelece como isto será obtido, sendo necessário que o conceito seja melhor esclarecido para que, quando não se puder inferir a causação, o mesmo possa ser utilizado.

Uma terceira alternativa consiste em efetuar uma sintonia fina no conceito de coerência trabalhando com a definição de coerência vertical proposta por de Haas.

De Haas et al. (2000:580) ao analisarem relações existentes entre indicadores de desempenho e seu efeito na organização afirmam que existirá uma coerência vertical quando melhorias nos indicadores das equipes operacionais provocarem maior eficácia na organização.

No nível de atividade a coerência está relacionada com a ligação entre metas e recursos de cada processo com as metas da empresa, e ela se dá numa perspectiva vertical, seguindo uma determinação hierárquica, de cima para baixo e, também, com base nos resultados dos diálogos estratégicos, que usam a contribuição dos níveis inferiores, de baixo para cima.

Portanto, o processo de fixação de metas, considerado um instrumento crucial para alcançar os objetivos nos diferentes níveis da organização, fará uso contínuo do diálogo estratégico compondo as perspectivas verticais e horizontais, visando a coerência das metas organizacionais, seja da alta direção, seja de seus demais membros.

Estudos demonstraram que a existência daquele diálogo (participação) na definição de metas estratégicas da organização reduziu o grau de conflitos na fixação de metas.

Uma quarta alternativa a seguir residiria na metodologia do OVAR que se constitue em alternativa às metodologias que enfatizam a causalidade, apoiando-se nas já testadas qualidades do BSC e fazendo uso da congruência entre metas e objetivos.

A definição de congruência para uma medida de desempenho é dada por Bushman (Bushman,1999:2; Feltham, 1994:430) como sendo o grau de alinhamento entre o efeito da ação do agente na medida de desempenho e seu conseqüente efeito sobre o valor da empresa.

O uso da congruência foi desenvolvido à partir da nova economia institucional, onde, por exemplo, os acionistas de uma empresa não são as mesmas pessoas que a administram, surgindo problemas de agenciamento. Ou, ainda, na gestão com base no valor, questiona-se como alcançar valor se não há congruência entre as metas e sua comunicação, na ótica dos acionistas e gestores? Neste caso tem-se como elemento fundamental que a qualidade da comunicação entre acionistas e gestores está condicionada a assumir que a estratégia é algo claro e amplamente conhecido pela estrutura e não considerá-la como um processo coletivo e incremental.

Martin e Petty (2000) propõem que as contribuições de indivíduos e grupos para a criação de valor para os acionistas sejam mensuradas utilizando suas medidas de desempenho e que as recompensas sejam estruturadas de acordo com o critério de que quanto maior a congruência dos objetivos, maior a recompensa. Assim, a falta de congruência de uma medida de desempenho provoca custos de agenciamento para o acionista.

O gestor com acesso às informações sobre o efeito de suas atividades nas medidas de desempenho e no valor da empresa pode estar sujeito a perdas de congruência decorrentes de sua má alocação de um determinado esforço. Para se proteger ele irá ajustar as características da medida de desempenho em detrimento do acionista. 
Quando a informação sobre o desempenho do gestor gerar dados sobre o valor da empresa e sobre as medidas de desempenho, cria-se a oportunidade daquele se beneficiar da delegação, onde o que conta é a correlação entre o valor da empresa e as expectativas sobre as medidas de desempenho.

Portanto, congruência é uma correlação ex-ante entre o valor da empresa e as medidas de desempenho e, em determinadas situações, o uso das informações pessoais do gestor irá encontrar a congruência determinando o valor da delegação. Assim, quando ele tem acesso a informações sobre seu desempenho define-se um limite do nível de congruência, abaixo do qual a delegação não tem valor. Vale mencionar que uma congruência de metas é interessante sob a ótica normativa de que é "bom" para a organização se sua atenção se voltar para uma direção estratégica coletivamente compartilhada.

\section{REFERÊNCIAS BIBLIOGRÁFICAS}

BEISCHEL, Mark E., SMITH, K. Richard. Linking the Shop Floor to the Top Floor. Management Accounting, October, 1999, p. 25.

de HAAS, Marco, KLEINGELD,A. Multilevel Design of Performance Measurement Systems: Enhancing Strategic Dialogue Throughout the Organization. Management Accounting Research, 10, 1999 , p. 233

de HAAS, Marco; ALGERA,J.A.; van TUIJL,H.F.J.M.; MEULMAN,J.J. Macro and Micro Goal Setting: In Search of Coherence. Applied Psychology: an International Review, 2000, v. 49 (3), p. 579.

ECCLES, Robert. The Performance Measurement Manifesto. Harvard Business, 1991.

EDVINSON,L.; MALONE, Michael S. Conhecimento Empresarial, São Paulo, Makron Books, 1998, p. 21

EPSTEIN, Mark; BIRCHARD, B. Counting What Counts, Turning Corporate Accountability to Competitive Advantage, Perseus Publishing, Harpers Collins - New York, 2000.

FELTHAM, Gerald A.; XIE. Performance Measure Congruity and Diversity in Multi-Task Principal/Agent Relations. The Accounting Review, 1994, July, Vol. 69, No. 3, , p. 429-453.

FREEDMAN, Milton. Essays in Positive Economics, University of Chicago Press, 1953.

GRADY, M. W., Performance Measurement: Implementing Strategy, June, pg 49

GRANGER, CWJ, 1998, Causal Inference, Publicado em The New Palgrave - A Dictionary of Economics, Edited by John Eatwell, Murray Milgate; Peter Newman. Volume $1-$ A to D. Macmillan Press, Limited, Londres.

GUJARATI, Damodar N. Econometria Básica. Makron Books do Brasil Editora Ltda. Terceira Edição, 2000.

HERTENSTEIN, Julie, PLATT, M. Performance Measures and Management Control in New Products Development, Accounting Horizons, 2000, 14, 3, p. 307.

HICKS, John., 1979, Causality in Economics, Basic Books, Inc., New York. 
ITTNER, 1998, Christopher, LARCKER, D. Innovations in Performance Measurement: Trends and Research Implications, Journal Of Management Accounting Research, 10, p. 205

JONES, Thomas, SASSER W., 1995, Why Satisfied Customers Defect, Harvard Business Review, Nov-Dez, p. 88

JR. HAIR, Joseph F; ANDERSON, Ralph E.; TATHAM, Ronald L.; BLACK, William C., 1998, Multivariate Data Analysis, Prentice Hall, New Jersey, Fifth Edition.

KAPLAN, Robert, NORTON, D. Linking the Balanced Scorecard to Strategy. California Management Review, Fall, 4, 1996, p. 53

KAPLAN, Robert, NORTON, D. A Estratégia em Ação - Balanced Scorecard. Rio de Janeiro, ed. Campus, 1997.

KAPLAN, Robert, NORTON, D. Having Trouble with Your Strategy? Then Map It. Harvard Business Review, September-October, 2000, p. 167

KERLINGER N., Fred. Metodologia da Pesquisa em Ciências Sociais - Um Tratamento Social. E.P.U. - Editora Pedagógica e Universitária Ltda., São Paulo, 1980.

KÖCHE, José Carlos. Fundamentos de Metodologia Científica - Teoria da ciência e prática da pesquisa. Petrópolis, RJ: Editora Vozes, 17ª Edição, 1997.

KUENG, Peter. Process Performance Measurement System: A Tool to Support Process-Based Organizations. Total Quality Management, Jan, 2000, p. 67

LALANDE, André. Vocabulário Técnico e Crítico da Filosofia. Livraria Martins Fontes Editora Ltda., 1999.

MAISEL, L.S. Performance Measurement: the Balance Scorecard Approach. Journal of Cost Management, Summer, 47, 1992.

MARTIN, John D. e PETTY, J.Willian. Value Based Management. Harvard Business School Press, Boston, 2000.

McNAIR, Carol j., CROSS,K. Do Financial and Non Financial Performance Measures Have to Agree?. Management Accounting, November, 1990, p. 28

MICHEL, Daniel, Le Contrôle de Gestion, HEC Coll, Dunod 1998

MORA, J; Ferrater. Dicionário de Filosofia. Tomo I, Ed.Loyola, S. Paulo, Brasil, 2000.

NORREKLIT, Hanne. The Balance on the Balanced Scorecard - a Critical Analysis of Some of its Assumptions. Management Accounting Research, 11, 2000, p. 65.

PORTER, M., 1989, Vantagem Competitiva, Ed. Campus, RJ

REICHELSTEIN, Stefan. Investment Decisions and Managerial Performance Evaluation Review of Accounting Studies, 2. 157-180. Kluwer Academic, Boston, 1997. 
REICHELD, F.F., SASSER, W.E. Zero Defections: Quality Comes to Services. Harvard Business Review, Sept-October, 1990, p. 105

ROSEN, Harvey S, 1995, Public Finance, 4th. Edition. Irwin, Chicago.

RUCCI J., Anthony, KIRN, P. Steven and QUINN, Richard T. The Employee-Customer-Profit Chain at Sears. Harvard Business Review, January/February, 1998.

SIMON, Herbert A. Causality in Economic Models, Publicado em The New Palgrave - A Dictionary of Economics, Edited by John Eatwell, Murray Milgate; Peter Newman. Volume 1 - A to D. Macmillan Press, Limited, Londres, 1998.

SIMON, Julian L. The concept of causality in Economics, Kyklos 23, 1970, p. 226-52.

SIMONS,R. The Strategy of Control, CA Magazine, March, 1992.

THE NEW PALGRAVE - A Dictionary of Economics. Edited by John Eatwell, Murray Milgate; Peter Newman. Volume 1 - A to D. Macmillan Press, Limited, Londres, 1998.

TURNEY, P. Activity Based Management: Making the Investment in Quality Count. American Accounting Association, Albuquerque New Mexico, 1992. 